\title{
高聚物結晶研究的进展
}

$$
\text { 徐 端 夫 }
$$

（中国科学院化学研究所）

近来高聚物在各个方面都得到了广泛的 应用和极为迅速的发展，这是因为它的各种 性稹比起旧有的小分子物盾来有許多特点和 优点。为了更好地发展这門科学, 进一步改 进高聚物的性能，就必須閣明高聚物具有这 些特性的本稹，梁入地了解高聚物的結构。 因此，高聚物的結构、性能以及結构和性能之 間关系的研究是一个很受重視和很有兴趣的 研究課題。对高聚物溶液性貭的大量研究, 搞清楚了許多根本的問題，例如知道了这是 一些分子量很大 (几万至几百万) . 的鏈状分 子，是分子量大小不均一的多分散体系，等 等。然而在另一方面，关于高聚物固体的結 构, 这个对性能有直接密切联系的更为重要 的問題，我們却了解得很不够。过去虽然也 进行了不少关于高聚物固体結构的研究, 得 到一些知識和建立了高聚物的結构模型和学 說，但是其中有些概念是錯誤的。这些不正 确的概念广泛地流传了二三十年，大大地阻 碍了我們正确地了解高聚物的結构問題。直 到最近五六年来，对高聚物晶态結构和結晶 轉变过程进行了許多研究，才漸漸搞清楚一 些比較重要的規律，使得我們对高聚物晶态 結构的訩識慢慢地正确起来。本交将簡短地 把这些比較重要的碑究結果及由此建立起来
的新概念，作一概括的介紹。

\section{一 罯聚物結晶的传統摡念}

从外覌看来，高聚物和小分子結晶物稹 很不相同，它不具有規則的几何外形和固定 不变的对称性, 而是“无定形”的物貭。最早 用 X一射綫結构分析的方法来研究高聚物內 部微观結构的是日本人 Nishikawa 和 Ono ${ }^{[1]}$, 他們在 Laue 发現晶体对 $\mathrm{X}$ 一射綫能产生衍射 效应的第二年 (1913 年) 就首先应用这个威 力強大的工具来研究䊹維素的結构。根据实 驗結果,他們誩为: “䊹維素中含有許多取向 本行于䊹維軸的微小晶粒。”用 X-射綫衍射 法研究了許多高聚物的微覌結构, 发現含有 微小晶粒的微晶物稹虽然没有一定的規則宏 覌外形，但是每个晶粒內部的結构却象普通 的晶体一样具有三維长程有序的点陣結构。 而另外有許多高聚物，例如聚苯乙烯、聚甲 基丙烯酸甲酯等則具有真正的非晶态結构， 它們不仅没有規則的究覌外形，而且微覌的 結构，師原子分子的排列也是无序的，不具 有三維长程有序的点陣結构。因此按照微观 結构的不同，可以把高聚物分为結晶性高聚 物和非晶态高聚物两个大类。前者在适当的 条件下能够自发地生成許多微小的晶粒，成 
为微晶物盾，而后者則不能够結晶。組成微 晶物盾的微小晶粒的大小，根据 $\mathrm{X}$ 一射綫行 射綫变宽的方法和 $\mathrm{X}$-射綫小角度散射长周 期的測量，估計約为 $100 \AA$ 左右。用热力学 的方法对許多結晶性高聚物进行了广泛的研 究，也一再发現它們都有一級相轉变，証明 的确具有覓正的晶体結构。許多結晶性高聚 物的 X-射綫衍射图，除了有粗大的衍射点 以外（如果是没有取向的試样則为較尖細的 衍射綫)，还常常有一两个㵐散的衍射圈， 这个現象和 $\mathrm{X}$-射綫对液体的衍射效应十分 相似。Gerngross ${ }^{[2]}$ 等根据上述这些現象和高 聚物的其他特点，例如綫型分子伸展时可长 达几千埃以上，其中有些分子輍长，有些分 子較短，长鏈分子有柔順性，易于相互緾結 讲傾向于卷曲起来等等，提出了高聚物具有 两相結构的模型和学說(图 1)。这个学說訓

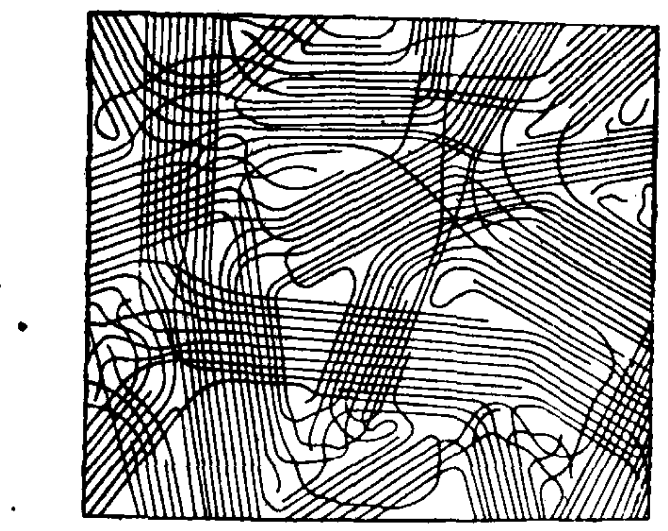

图 1 高聚物的两相結构模型示意图

为，既然綫型的长鏈分子伸展时要比晶粒的 大小长出好几十倍，那末一个高分子鏈可以 同时貫穿几个較小的晶区和非晶区。在非晶 态时，高分子鏈是相互䌅結卷曲的。当它們 結晶时，相互本行取向的分子鏈段就进一步 規則排列起来形成微小晶粒，晶粒沿着分子 鏈方向生长变大，也沿着垂直于分子鏈的方 向增长变大，生成大約 $100 \AA$ 左右的微小晶 粒。結晶过程可以同时在一个分子鍵上的几
部分发生，同时长大成几个微小的晶粒。由 于高分子鏈是卷曲縓結的，分子鏈不易运动 等动力学因素以及高分子鏈結构不規整等热 力学因素，高聚物結晶时总不能完全結晶， 而只能部分結晶; 有晶区，同时还存在着没 有轉变的非晶区，也就是說它具有两相同时 关存的特殊結构状态。这个学說訩为, 結晶 性高聚物是由分散在非晶态介盾中的許多微 小晶粒(大小仅 $100 \AA$ 左右)組成的。因为分 子鏈同时貫穿晶区和非晶区，所以在它的晶 相和非晶相之間没有一个明确的相界。粗看 起来，結晶性高聚物两相結构的模型和学說 似乎很有道理, 因为它可以解释高聚物的 $\mathrm{X}$ 射綫衍射图，高聚物的密度䡛理論值为低， 高聚物的紅外吸收光譜，核磁共振以及力学 性稹等許多实驗現象，因此很快地就为大家 所接受和公䚸，成为教科书中必㹬的經典概 念。但是如同其他不正确的学說那样，两相 結构的模型和許多另外的实驗事实存在着矛 盾；因而漸漸引起了人們的怀疑。Каргин ${ }^{[3]}$ 学派根据高聚物的堆砌密度、松弛过程和結 晶速率等研究，对这个結构模型提出异議。 这个模型也无法解释高聚物結晶时生成的形 态結构。然而反对这个結构模型最強烈、最 值接的証据，应該归功于高聚物单晶体的发 现和对高聚物单晶体的結构所进行的樑入㸴 究 $^{[4]}$ 。

\section{二 高聚物单晶体的发現和它 的褶迭鏈結构}

結构規則的天然高聚物，例如蛋白稹， 能够培养成为具有規則外形的晶体是人所拈 知的事实。杜仲橡胶 (Gutta percha) 从䍇液 中結晶也能得到消光規則的晶体 ${ }^{[5]}$ 。 Jaccodine ${ }^{[6]}$ 用电子显微鏡观察从溶渡中析出的聚 
乙烯，看到了晶体生长的蠌旋阶梯(1955年)。 两年以后，Keller ${ }^{[7]}$ 、Till ${ }^{[8]}$ 和 Fischer ${ }^{[9]}$ 用稀 溶液慢慢冷却的方法同时都得到了菱形薄片 状的聚乙烯单晶体(图 2 )。从图 2 这张电子 显微照片可以看到，聚乙烯的单晶体具有規 則的几何外形，同长鐩烷烴的单晶体十分相 象。而且根据电子衍射效应, 可以証明它的 內部結构也是排列得很有规則的, 的确是一 个单晶体。图 3 是聚乙烯单晶体的电子衍射 图, 可以看到它的衍射点很清晰, 很細。

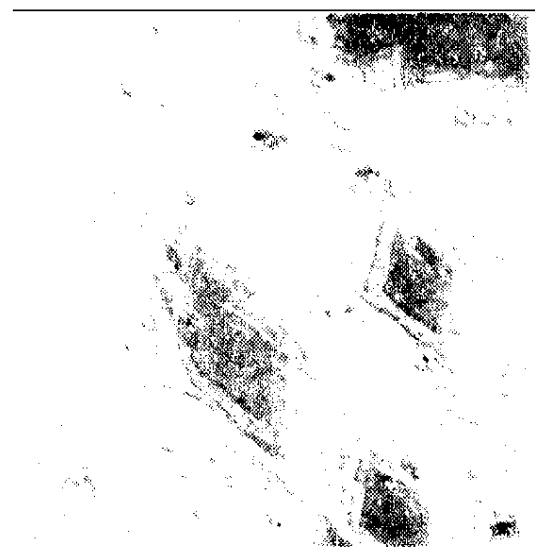

图 2 聚乙狶单晶体的电子显微照片

除了聚乙烯以外，对其他綫型高聚物也进行 了广泛的研究，发現聚甲醛 ${ }^{[0,11]}$ 、聚酰 胺 ${ }^{[12,13]}$ 、聚酯 ${ }^{[14]}$ ，各种有規立构的綫型高聚

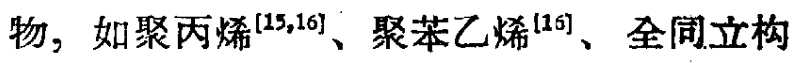

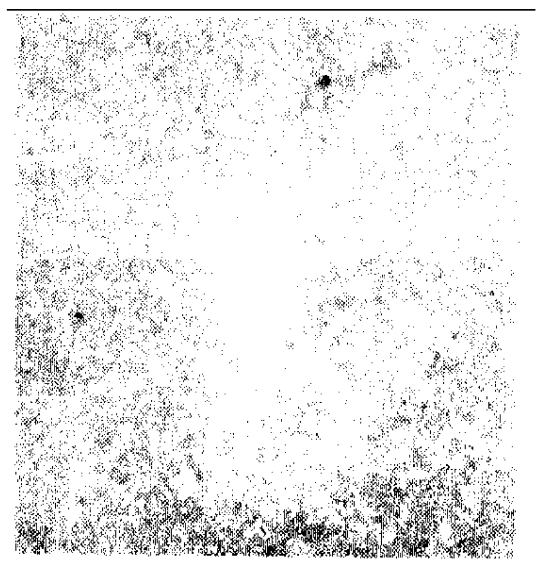

图 3 聚乙烯单晶体的电子衍射图

的聚4-甲基戊烯-1 ${ }^{[17]}$ 、結晶性的聚丙烯酸[18] 以及秆維素及其衍生物三醋酸糿維菜 ${ }^{[19]}$ 等 等，也都可以用极稀溶液慢慢結晶的办法培 养成为能用电子显微鏡甚至光学显微鏡看得 見的单晶体。这些晶体的几何外形，如同小 分子晶体一样，决定于晶体內部結构的对称 性和結晶生成时外界的条件。有些单晶体是 菱形的，六角形的，四四方方的薄片，例如 正交晶系的聚乙烯，六方晶系的聚甲醛，四 方晶系的聚 4-甲基戊烯-1（图 2、图 4、图 5)，而有些則是細长的針状物，例如三斜晶 系的尼龙 6,10 (图 6 )。

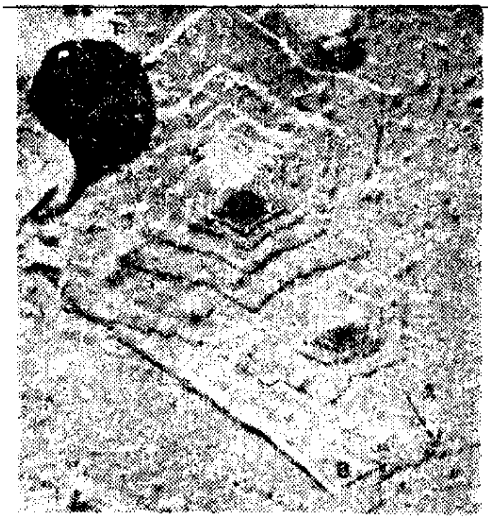

图 4 聚甲整单晶体的电 子显微照片

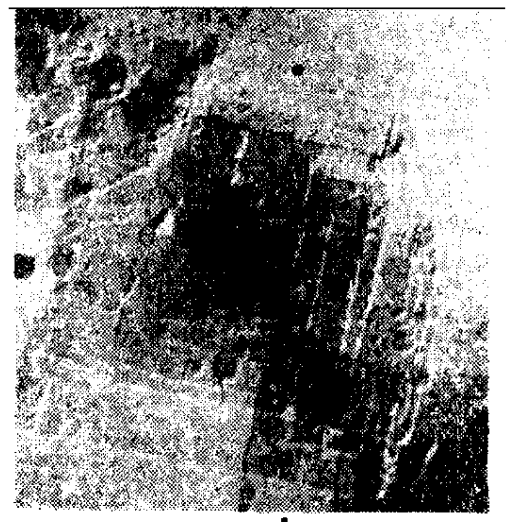

图 5 全同立构聚 4-甲基戊 䗋 -1 单晶体的电子显 微照片

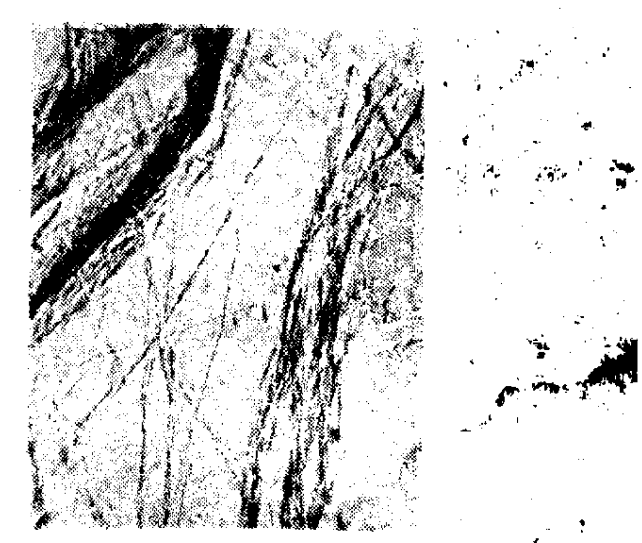

图 6 聚癸二酸已二酰胺 （尼龙 6,10$)$ 晶体的 电子显微澌片 
欧变楮晶的条件，同一个高聚物可以生成片 状晶体也可以生成針状晶体，例如聚酰胺、 洯 4-甲基戊烯-1、，聚醌等等。随着結晶条 件的不同，高聚物还能够生成繁晶 ${ }^{[20]}$ (图 7 ) 以及其他更为复杂的多晶聚集体一一球晶、 多角晶、树枝状結晶聚集体等等。

终 7 聚乙烯攀晶的电子显微照片

在一般情兄下制得的高聚物单晶体，大。 都是只有大約 $100 \AA \AA$ 厚的薄片或細針，而它 弗长度可大至微米的数量級。用电子衍射研 究这些单晶体的結构，发現高分子鏈的取向 科不沿着晶体最长的方向而是沿着它最短的 方向，即垂直于(或几乎垂直于)薄片的平面 “或垂值于針的方向。根据分子量的測定，我 門已經知道綫型高分子伸展时的长度可达几 千、几万埃，而薄片晶体及針状晶体的厚度 却只有几十到几百埃。在晶体中伸直了的大 亦子将怎样能够很规則地安排在这个薄薄的 写尚昵？Keller 考了有机化合物晶体結构 研究的結果，提出了长鏈分子在晶体中具有 褔迭鐩結构的解释。他訜为，在晶体中高分 子可以几乎不改变原有的鍵长鍵角很规則地 进行反复禇迭。图 8 是褶迭鏈結构的示意 图。

所有进行研究过的高聚物评晶休都普遍 地証实具有褶迭鏈的結构。因此，福迭鐩結 构不是聚乙烯或某儿种高聚物結晶的特殊现

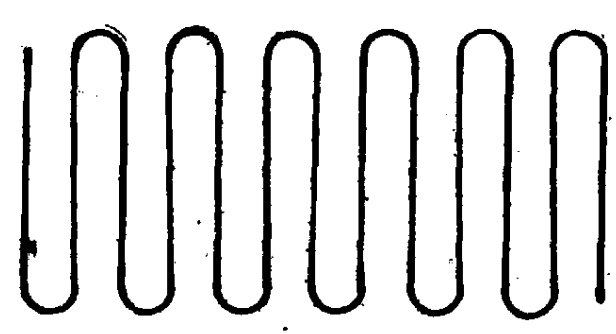

图 8 整迭縺結构示意图 (平面譛迭)

象，而是高聚物結晶时的基本規律。甚至那些 側基相当大或被訩为分子鏈相当刚性的高聚 物，在結晶时也都有着祤迭鏈的結构。一个 很有趣的現象是，当分子量足够大时,单晶体

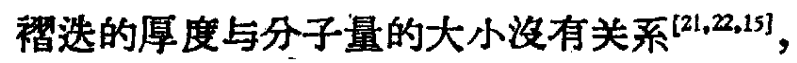
而只与結晶生成时的条件(如温度、溶剂等) 以及高聚物的本性有关8 这个特征, 可能是 当分子量足够大时，分子量对結晶性高聚 物許多性质关系不大的原因。分子鏈褶迭 的厚度一般从几十埃到几百埃，有一种䋨型 聚酷单晶体的厚度只有 30 埃 ${ }^{[14]}$ ，据研究它 是以化学結构的重复单元来进行福迭的。为 什么高聚物結晶时分子鐩要如此規則地反复 裙迭，而被迭的厚度又大致都在 $100 \AA$ 左右 呢? 文献中曾經有过不少解释 ${ }^{[23-2]]}$ ，現在看 来最合理的解释是热力学的說明[28,20] ; 即高 聚物在結晶时傾向于生成具有最低自由能密 度的晶体。僌短的禇迭生成輘薄的晶体, 将 增加它的表面能，这个因素使結晶傾向于变 厚，而分子間相互作用則希望分子鏈福迭得 短一些。分子鐩的榅迭长度决定于这两个相 反因素之間自由能密度的极小值。高聚物結 晶时除了能生成片状和針状的結晶以外，为 了有利于減少分子鏈福迭时褶迭部分的空間 阻碍，常常褶迭成斜面状結构(示意手图 9), 生成一种特殊的空心稜錐状晶体 ${ }^{[10,30,31]}$ 。图 10 是聚乙烯空心稜錐晶体的电子显微照片, 可以看到它由好几层空心稜錐状晶体組成， 武样經干燥后貼紧在支持物上，晶体被压平 
后中央部分隆起許多裮被不本之处，其边緣 有二处裂开。

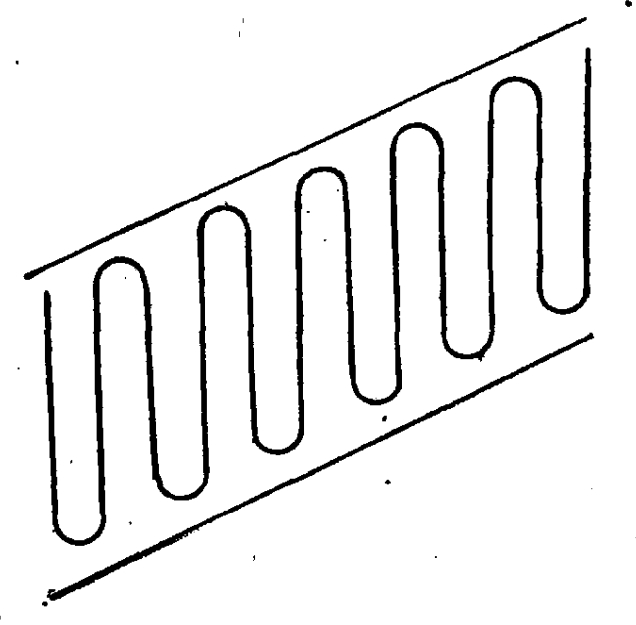

图 9、傾斜橁迭薄片示意图

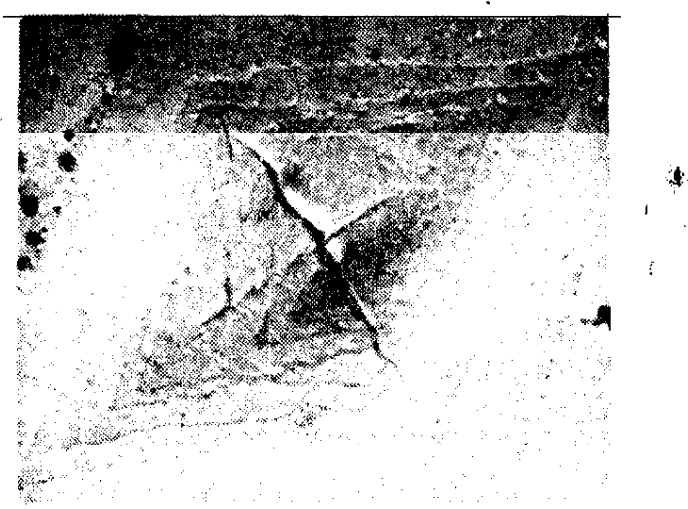

图 10 聚乙烙空心稜錐晶体的电子显 微照片，晶体被压平后中央部分隆起 許多㛃铍，其边緣有一处裂开

图 11 是空心稜錐状晶体的示意图，表示出 它是由四片联生在一起的片状单晶体組成 的。高聚物这种有趣的結晶形态，可能是造 成拉伸秆維試样經热处理后它們的 X-射綫 '小角度散射图由层綫分裂成为四点图的原 因 ${ }^{[32-37]}$ 。图 12 是聚对苯二甲酸乙二酯䊹維 的 X一射綫小角度散射炤片。試样經热处理 后层綫分裂成为四点。

以上我們介紹了高分子鏈怎样規則地褶 迭起来，二維长大成为一个片状的晶体。实 的晶体当然不致只有一层薄片而是由許多 层滇片租成的。那末这些薄片又是怎样堆砲

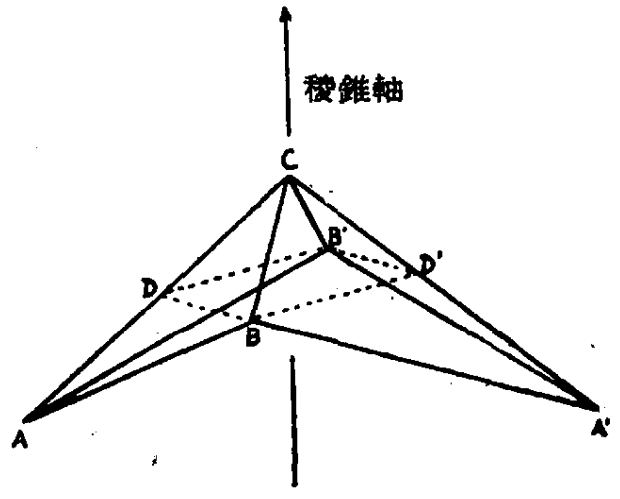

图 11 聚乙烯空心稜䤳晶体的示意图， 表示晶体由四片单晶体等生栭成

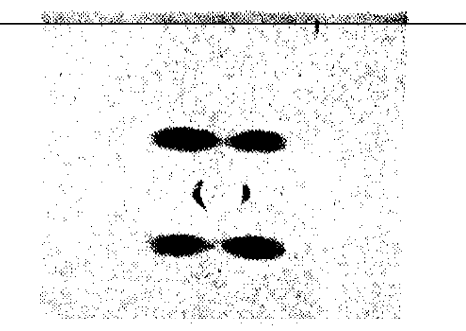

图 12 聚对苯二甲酸乙二酯 种維的 X射綫小角度散射照片，縒样經热处理后 层綫分裂成为四点

起来生长成为䡯厚的晶体呢? 䂰究小分子結 晶生长的規律已經建立了一些理論。这些理 論訩为，晶体在生长时，原子、分子（或离 子）是一层一层，一行一行地长到晶面上去 的。原子分子在晶面上堆砌好象㦈大楼砌磷 墙那样，砌完了一层再砌上面一唇，在一层 中砌满了一行再砌另一行。在一个本整的晶 面上要生长一层新是是相当困难的。因为由 于分子在不断地热运动，几个孤零零地吸附 在晶面上的分子是不稳定的，很容易从晶面 上脫离出去，只有当比較多的分子聚集在一 起形成一个較大的晶核才能稳定下来。可是 許多孤立的、运动着的分子聚集在一起的机 率很小，因此在一个理想的本整的晶面上生 成新的晶核的速率很慢，也就是說理想晶体 的变厚速率极慢。但是实际晶体的生长速率 远远超过理論計算的結果，为了解决这个分 
歧，Frank于 1949 年提出了著名的結晶生 长位錯理論 ${ }^{[35]}$ 。他說，在实际晶体中，原子 分子的排列种不非常理想規則而有着好些排 列得不整齐的地方，郎有位錯。位錯使得晶 体不十分平整，而有一些凹凸不平的部分，

結晶生长时新层就沿着这个凹凸不本的中心

螺旋位錯中心一层一层地不断向上盘旋 生长变厚。根据这个理論，他預測如此生长 成的晶体是一个带有缺陷的晶体，这种缺陷 晶体的生长面将不是一个面正的平面，而在 其最終的晶面上将留下一个螦旋状的生长阶 梯。晶体沿螺旋阶梯生长变厚的各个阶段示 意于图 13 中。
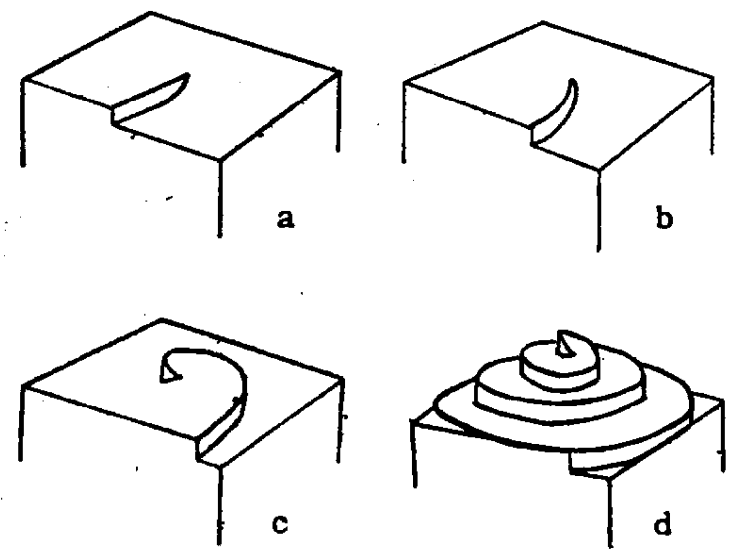

图 13 結晶沿螺旅位錯中心不断盘旋生长 变事机制的示意图。a， b、c、d 各表示生长 的不同阶段

科究小分子結晶生长的过程，一再覌察到留 在結晶生长面上的螺旋阶杨 ${ }^{[36]}$, 証实了 Frank 的預測，强有力地使人信服他所提出的結晶 生长位錯理論。近年来对高聚物結晶生长的 研究，各种高聚物不論从溶液結晶或从熔体 結晶，也都多次看到了結晶生长的螺旋阶 梯，証明高分子結晶生长的机理与小分子結 晶生长的基本規律是共同的。仔細覌察图 2、图 4 两张电子显微照片，可以发現聚乙 烯和聚甲醛的单晶体不是簡单地由孤立的薄 片堆砌起来的，而是由薄片結晶連結不断地
沿位錯中心盘旋增长变厚而生成的。图 14 是綫型聚酯单晶体的电子显微照片，可以更 清楚地看到結晶生长的螺旋阶梯。图 15 是 聚四氟乙烯熔体結晶試样表面的电子显微炤 片，同样也可以看到結晶生长的螺旋阶梯。

图 14 型聚睻单晶体的电子显脱片。 有很清楚的結聂生长赫旅阶梯

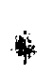

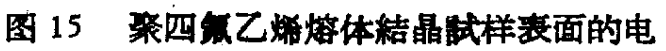
子显微照片。有明显的层状結构和結昆生 长的蝠施阶梯

高聚物熔触体冷却时，結晶生长的过程 可能比从极稀溶液培养高聚物单唱体的过程 要复杂得多，浔有办法从熔融体中找到、挑 出所生成的单晶体来进行研究, 熔虽体結晶 时往往生成組糡很复杂的多晶浆集体。有时 結晶轉变过程非常迅速，只需几分鈡甚至几 秒鈡郎可完成結晶过程。然而尽管高聚物从 熔体結晶时有許多不同于从极稀溶液中慢慢 結晶的地方，塔体結晶的高聚物依然象从溶 液中慢慢結晶那样，傾向于生成片状及針状 
的結构，在片状体及針状体中分子鏈也依然 都是規則褶迭的。用电子显微鏡研究高聚物 熔体結晶生成的表面，或䢃开所生成的块状 多晶聚集体，覌察熔体結晶物体的內部結 构，发現所有这些高聚物，聚乙烯 ${ }^{[9]}$ 、聚丙 䟦 ${ }^{[37]} 、$ 聚甲醛 ${ }^{[38]} 、$ 聚酰胺十一(尼龙十一 $)^{[9]}$ 、 聚三氮氮乙烯 ${ }^{[9]}$ 、聚四氟乙烯 ${ }^{[39]}$ 等等都具有 智迭鏈的层状結构，各种分子鏈的禇迭长度
也都大致为 $100 \AA$ 左右。这些片状結晶也都 沿着螺旋位錯中心生长变厚，在結晶的生长 面上有結晶生长的螺旋阶梯。图 16 是聚乙 烯熔体結晶試样裂面的电子显微照片。图 17 是聚四㡘乙絺熔体結晶試样裂面的电子显微 照片。图 18 是聚三氟氯乙烯的电子显微照 片。可以看到烚体的表面及其内部都有很清 楚的层状結构。

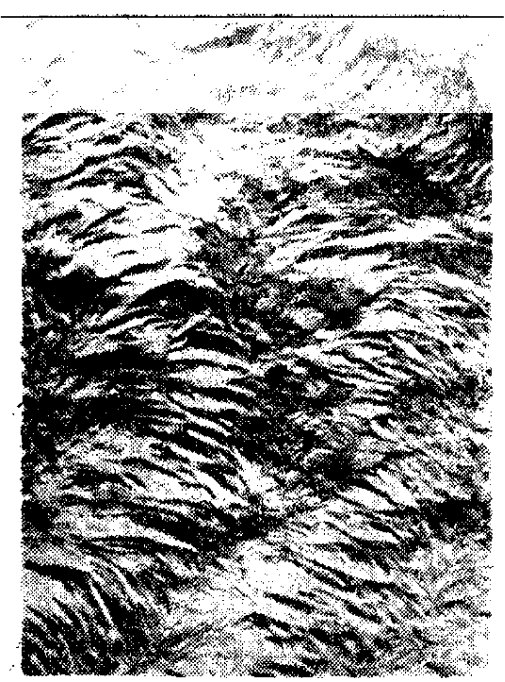

图 16 聚乙烯熔体結晶試 样裂面的电子显微照片

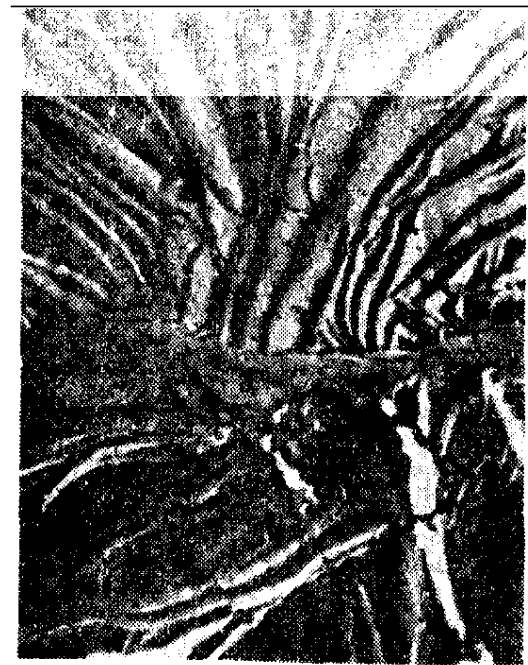

图 17 聚四氧乙烯試样裂面 的电子显微照片

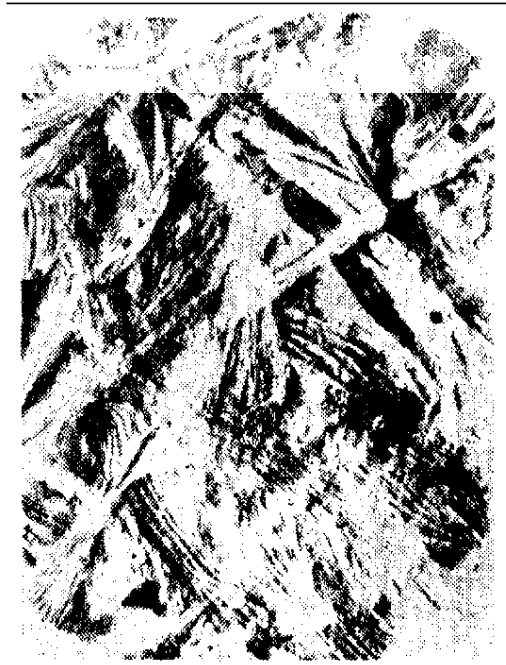

图 18 聚三戒氮乙烯的电 子显㣲照片

\section{三 海聚物結晶聚菓体一一球晶和多角晶}

高聚物結晶时，除了在适当控制的条件 下（例如用极稀的溶液，控制适当的温度使 之慢慢結晶）可以培养得到单晶体以外，在 通常情况下不論从溶液或从熔融体冷却結 晶，都傾向于生成比单晶体更为复杂的組織 单元。这种組織是由无数个微小的晶粒，按 照結晶生长的一定規律长在一起而成的多晶 聚集体。通常它是呈球状的，所以叫做球 晶*。球晶的值径可大至几十几百微米或长 一得更大（与单晶体薄片的厚度相比，大了一 万倍)，因此可以用普通的光学显微鏡或偏 米显微鏡直接看到它們的形态。球晶結构是
高聚物熔体結晶的基本形态，是使得結晶性 高聚物呈現乳白色不透明的原因。

在球晶中微小晶粒按炤一定的方式規則 地排列起来，因此用正交偏光显微鏡进行观 察，可以看到它具有規則的消光图诨。最常 見到的是具有黑十字消光的球晶。图 19 是 聚硞氧烷球晶的偏光显微照片（加正交偏振 片照相），可以作为高聚物球晶結构的典型 代表。在这种球晶中，微小的晶粒在正交偏 振片的偏振方向有本行消光，因此可見黑十

* 球晶和鋪球是完全不同的两种結构单位，前者是由 无数单晶聚集在一起的大結构单元, 直径約为数十 微米; 而后者是由一个或几个分于跬在稀溶液蒸发 时生成的小結构单元, 直径很小, 只有 $100 \AA$ 左右 或更小。 
字的消光图案。按照球晶光学性盾的不同， 可把它們分为正光性球晶及負光性球晶两 类, 前者牛径方向的折射率大于切綫方向的 折射率，后者相反，牛径方向的折射率小于 切綫方向的折射率。在偏光显微鏡下，球晶 除了有黑十字的消光图形以外，还常常呈現 明显的从中心向外发散的束状結构(图19)。
图 19 聚硅年烷球晶的偏光显微照片 （加正交偏振片）

随着結晶时球晶生成的条件不同，組成球晶

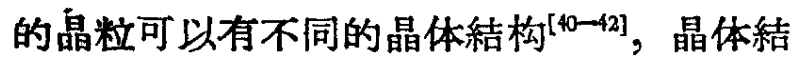
构相同的晶粒因为結晶条件的变化，在球晶 中取向排列的方式也可以各不相同，因此同 一一种高聚物有时能生成負光性的球唱，有时 能长成正光性的球晶 ${ }^{[33,44]}$ ，或者长成具有其 他消光图形的球晶，例如有些消光黑十字可 以变成鋸齿曲折状，歪拂起来，甚至生成没 有消光黑十字却有一系列同心消光圆环的球 晶 [1]。研究各种各样光学性盾不同的球晶的 一部結构, “发現尽管它們的光学性稹各不相 闹，㫜是分子鏈在球晶中排列的方向却有一 个共同的岾点，郎高分子鏈的方向总是垂直 于球晶的半径力向。用电子显微鏡研究球 晶, 可以很清楚地泊到它是由許多径向发散 的小薄片或小針組成的。根据球晶的光学性
盾，球晶中小区域的行射图及球晶的电子显 微鏡覌察等許多方面的研究結果，可以䚯为 球晶是純粹由微小晶粒組成的多晶聚集体， 在球晶中晶粒以一定的方式扭曲生长成为扭 曲的小条(图 20 是微小晶粒沿球晶半径方向 生长成扭曲小条的示澺图)，許多扭曲的小 条同时从一个中心向四面八方生长发展成为 一个球状的聚勧体 ${ }^{[5]}$ 。最近用溶剂腐蝕的方 法溶解掉球晶中部分晶粒，然后用电子显微 鏡覌察它的結构，很清楚地值接看到了这种 扭曲起来的小条 ${ }^{[14]}$ ，有力地值接証明了这个 最初根据球晶的光学性盾、 $\mathrm{X}$ 一射綫衍射等 研究提出来的結构模型。

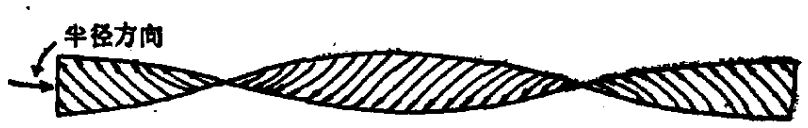

图 20 微小晶粒沿球晶牛径方向生长咸扭 曲小条的示意图

球晶的宏覌外状的确是球状的，用溶树 腐蝕的方法溶解掉球晶四周的非晶态高聚 物，可以清楚地看到它貝正的形状; 覌察球 晶的切片也証实它是球状物。它之所以成为 圆球状体，是因为組成球晶的从中心向外发 散的扭曲小条在結晶生长时生长速率相同的 線故。因此宏观看来，它的外緣是圆的。而 实际上，这些扭曲小条的尖端的微覌結构是 凹凸不平的。有时在慢慢生长的大球晶中， 可以清楚地看到球晶边緣凹凸不平的現象。

改变結晶生长的条件，結晶性高聚物除 了生成球晶以外，有时还能生成其他形状的 多晶聚集体。Geil ${ }^{[46,38]}$ 覌察聚甲醛熔体慢慢 結晶，发現一种六角形的多晶聚集体一一六 角晶。图 21 是聚甲醛六角晶的显微照片 (用 傾斜光照明覌察照相)。聚甲醛从溶液結晶 也能生成六角晶 ${ }^{[10,47]}$ ，其他高聚物如杜仲橡 


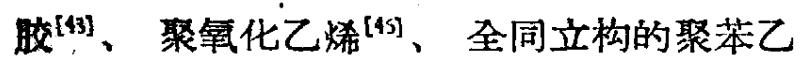
䟦 ${ }^{[41]}$ :三醋酸䊹維素 ${ }^{[50]}$ 等等也都能生成多角 晶。据 Geil 的研究，多角晶中分子鏈的取向 (郎晶粒的取向) 远較在球晶中規則得多， 不过多角晶仍然还是多晶聚集体而不是单晶 体。可以訩为，多角晶是单晶和球晶之間的 中間結构状态。

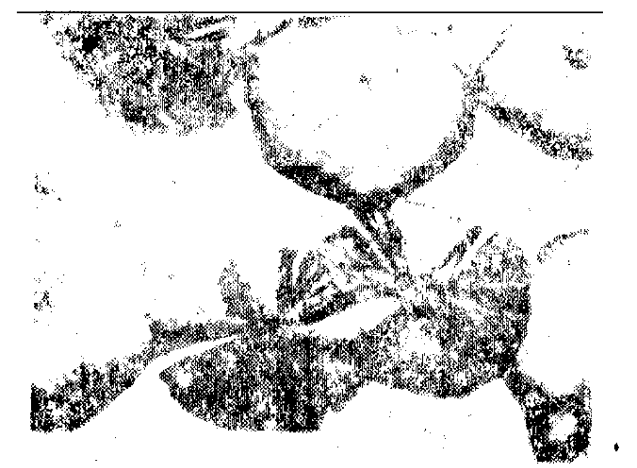

图 21 聚甲醛的六角晶和棜圆状結 晶聚集体(傾斜光照明)

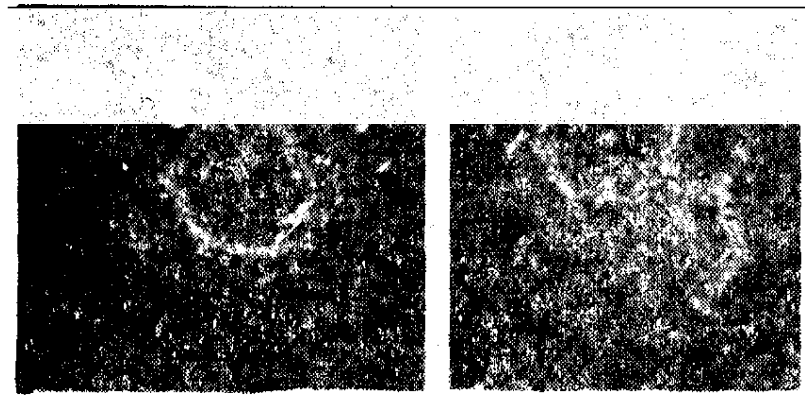

图 22 聚甲醍的六角环状結晶聚集体

高聚物結晶时，由于分子鏈排列得不整 齐，在薄片結晶的边緣产生很多位錯中心， 結晶生长时就沿着这些螺旋位錯中心迅速生 长变厚, 生成一种框架式的环状結晶聚集 体。四方晶系的聚 4-甲基戊烯-1 生成正方 形的环状体 ${ }^{[17]}$ ，六方晶系的聚甲醛則生成六

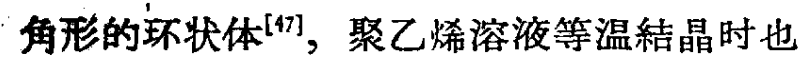
能生成环状結晶聚集体 ${ }^{[30]}$ 。根据电子显微鏡 的研究, 可以看到环状物的框架是由許多层
薄片状单晶体聚集而成的，它的中間也叛不 ，是真正空心的而有着一薄层很溥的片状晶 体。

結晶条件的变化，除了能够影响晶粒的 晶体結构, 改变球晶中晶粒的排列方式及影 响球晶、多角晶等各种不同的聚集状态的形 成以外，还会显著地影响所生成球晶的大小 和球晶数目的多少，也就是說，結晶生长的 条件可以大大地改变結晶性高聚物的聚集态 結构。而高聚物的这些聚集态結构对它的各 种性能有着非常直接的密切联系, 可以大大 地改变它的性能 ${ }^{[51]}$ 。因此，从工艺过程的角 度来看，人們对高聚物聚集态結构和聚集态 結构对性能的影响的研究，特別感到兴趣。 因而也就很自然地要求梁入了解这些結构状 态的本盾，这些結构的生成过程以及外界条 件对它們的影响，以便在加工过程中更好地 控制工艺过程，改进产品的貭量。

\section{四离聚物結晶动力学的研究}

如前所述，高聚物从非晶态到晶态的轉 变过程是一个很重要的問題, 为了樑入了解 这个过程的本稹，过去曾經进行了大量的䂰. 究工作。Mandelkern ${ }^{[32,53]}$ 写过两篇很好的文 献总結，評述了 1958 年以前的工作。近两 三年来，每年仍旧不断有許多关于这方面的 研究工作发表。

通常，大都朵用膨胀計法測量体积收縮 变化及用偏光显微鏡覌察球晶生长的办法， 来研究不同温度的等温結晶轉变过程。用膨 胀計法研究結晶过程时，先把封入在膨胀計 中的高聚物試样在真空体系中除气，干燥， 除去揮发性的小分子，然后加热到熔点以上 的温度使晶粒完全熔化，熔化完全后迅速把 膨胀計放入控制好温度的忹温槽中；使高聚 
物冷却到結晶温度，覌察膨胀計毛細管液柱 高度随时間的收縮来測量产生結晶的变化。

最初結晶轉变的速率很慢，有一个相当长的 时期几乎察党不到体积的变化，过了这段时 期以后，体积的收縮逐漸加快，最后当結晶 过程大部完成后，轉变的速率又逐漸变慢。

整条等温結晶曲綫(体积改变对时間作图)呈 反S形。图 23 是綫型聚乙烯的等温結晶曲 綫，可以作为高分子鏈結构規則的綫型高聚 物等温結晶曲綫的代表。

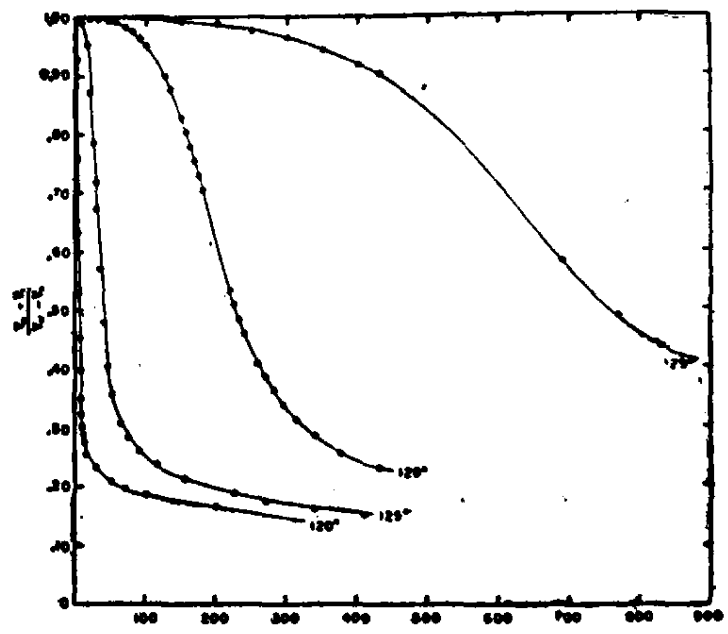

图 23 䋐型聚乙烯䛲体的等溫結晶曲綫图

照研究小分子物稹結晶轉变过程的方 法，用 Avrami 方程

$$
\theta=\exp \left\{-k t^{n}\right\}
$$

来处理高聚物等温結晶曲綫的数据，发現曲 綫前面很大部分都能符合 Avrami 方程的理 論計算值，只有曲綫的最后部分有些偏离。 式中 $t$ 为等温結晶的时間， $\theta$ 为 $t$ 时間占末 发生轉变物稹的百分含量。 $k$ 为結晶速率常 数， $n$ 为与結晶机制和結晶形态有关的常 数。分析等温結晶的实驗結果，可以証明高 聚物的結晶轉变过程也象小分子物稹的轉变 过程一样，分为从母相（非晶相）产生新相 (晶相)和新相(晶相)增长变大两个阶段。師
高聚物在結晶时，第一步由高分子規則地排 、列起来生成一个足够大的、热力学稳定的晶 核，这个阶段叫做結晶的成核过程; 第二步 則以晶核为基䂣，漸漸增长变大。高聚物結 唱时轉变速率的快慢，取决于晶核生成的速 率(每单位时間单位体积产生晶核的数目)及 晶核长大的速率。結晶速率随过冷程度而迅 速增加达一极大值，过冷程度継續增加結晶 速率又逐漸变慢。最初的結晶中心 (晶核) 可以是由非晶态高聚物有序排列起来直接生 成，这样产生的晶核叫做均相成核过程。也 可以由高分子吸附在固体杂盾的表面上而生 成，郎为异相成核过程。晶核生长时由于各 种因素的影响，可以一維生长成为針状体， 二維生长成为片状体，或者三維生长成为块 状体。結晶过程中成核、生长机制对 Avrami 方程中参数的影响如表 1 所示。

表 1 結晶轉变时成核和㙕长机制 对結晶参数 $n$ 的影响

\begin{tabular}{c|c|c}
\hline 粘晶增长方式 & 均 相 成核 & 开 相 成 核 \\
\hline 三維增长 & $n=4$ & $3 \leqslant n \leqslant 4$ \\
二維增长 & $n=3$ & $2 \leqslant n \leqslant 3$ \\
一維增长 & $n=2$ & $1 \leqslant n \leqslant 2$ \\
\hline
\end{tabular}

根据适当的結晶灵敏性稹（如体积、紅 外吸收光譜某些带的強度等）的变化来研究 結晶过程，只能測量总的結晶轉变过程而无 法直接覌察結晶生长的过程。为了补充膨胀 計法之不足，經常还用偏光显微鏡覌察球晶 生长的方法来研究結晶生长的过程; 直接测 量球晶长大的速率, 計数单位体积单位时間 生成球晶的数目来研究結晶的过程。用显微 鏡法研究結晶过程，可以判明結晶成核的机 制和覌察球晶結构等其他变化。膨胀計法和 显微鏡法的研究表明，結晶生长时体积的突 
变和球晶的出現和长大有着直接的密切联 系。球晶的出現是使高聚物变为乳白色不透 明的原因*。測量温度对球晶长大速率的影 响，发現在等温結晶时球晶半径增长的綫速 度为不变的常数, 郎球晶半径与結晶时間成 直綫关系。在熔点附近球晶增长的速率很 慢，随着結晶温度降低，其結晶速率迅速增 加达一极大值，再降低結晶温度，球晶增长 的速率又变慢。图 24 是全同立构聚苯乙烯 球晶生长速率对温度的关系，在 $175^{\circ} \mathrm{C}$ 时球 晶长大的速率最快。而用密度法測得它結晶 速率最快的温度是 $190^{\circ} \mathrm{C}^{[5+]}$ 。

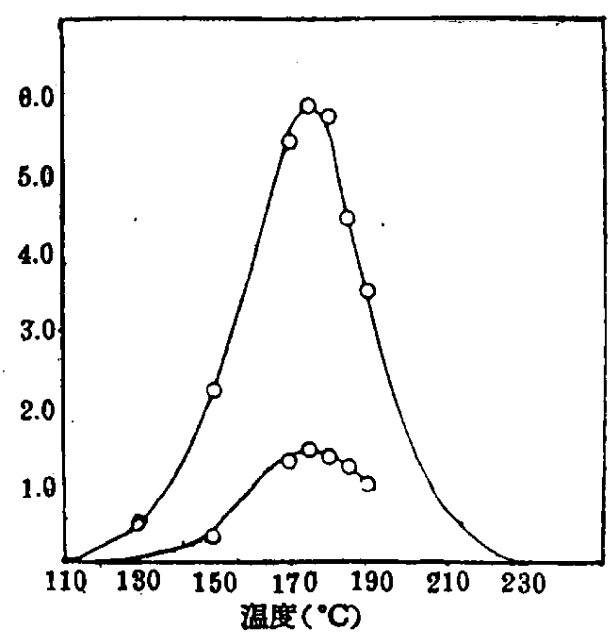

图 24 結晶溫度对全同立构聚苯乙 、烯球晶生长速率的关系

結晶温度稍稍改变，可以严重地影响結 晶速率的快慢。表 2 是聚癸二酸癸二酯結晶 温度对結晶速率常数的变化关系。可以看 到，仅仅降低 $6^{\circ} \mathrm{C} ， k_{s}$ 的变化竟达 $10^{15}$ 之多。 研究結晶温度对球晶生长速率的变化，注澺 到球晶生长速率极大的温度系数(图 25)，与 結晶成核过程和过冷程度呈指数关系变化相 比輘，証明球晶长大过程的快慢主要决定 于杂相成核的速率，郎主要决定于新的晶核 在球晶表面上形成的速率。高聚物結晶动力 学的研究，預期結晶过程以生成晶核及晶核
表 2 結晶溫度对聚癸二酸癸二酯結晶 速率常数 $k_{s}$ 的影响

\begin{tabular}{c|c|c|c}
\hline 溫 度 ${ }^{\circ} \mathrm{C}$ & $\begin{array}{c}k_{s} \\
\text { (膨胀計法) }\end{array}$ & 溫 度 ${ }^{\circ} \mathrm{C}$ & $\begin{array}{c}k_{s} \\
\text { (显徽鏡法) }\end{array}$ \\
\hline 72.6 & $5.51 \times 10^{-19}$ & 72 & $2.03 \times 10^{-18}$ \\
71.6 & $4.30 \times 10^{-16}$ & 71.1 & $6.84 \times 10^{-15}$ \\
70.7 & $4.32 \times 10^{-13}$ & 70.1 & $1.56 \times 10^{-12}$ \\
69.7 & $1.00 \times 10^{-10}$ & 69.1 & $5.00 \times 10^{-10}$ \\
68.6 & $2.38 \times 10^{-8}$ & 68.1 & $7.85 \times 10^{-8}$ \\
67.7 & $1.28 \times 10^{-5}$ & 67.1 & $2.02 \times 10^{-5}$ \\
67.7 & $1.50 \times 10^{-4}$ & & \\
\hline
\end{tabular}

增长的方式进行。这个結晶生长的机制和高 聚物单晶体生长的电子显微鏡呼究結果是一 致的。如前节所述，对各种高聚物单晶体进 行电子显微鏡覌察，都可以看到它們結晶时 总是先由高分子鏈进行犁迭生成晶核，从这 个最初的晶核发展长大成为片状体或針状

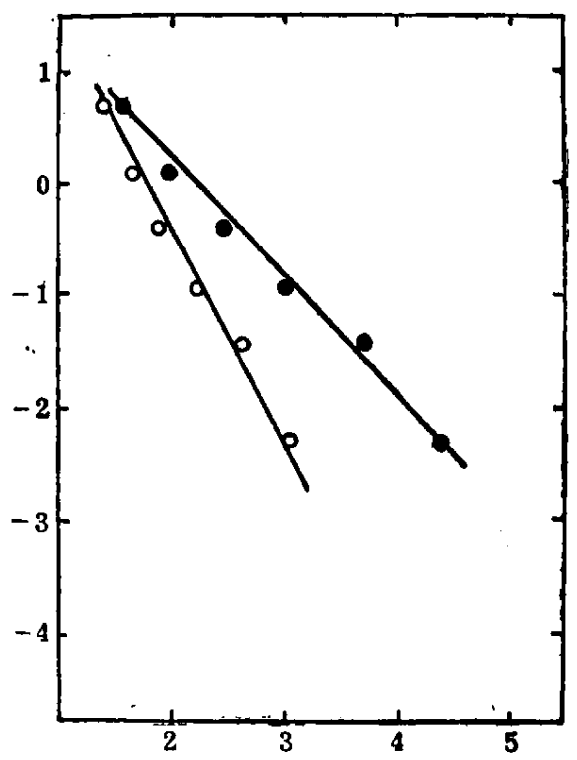

图 25 聚癸二酸癸二酯球晶綫性靚长速 率对数值 $\log k_{g}$ 对过冷程度的关系 [55]

* 最近研究聚硬脂酸乙烯酯的相轉变过程, 发現当体 积突变完成后高聚物由乳白色变为渾油牛透明, 需 継續加热至更高溫度，才变成完全透明的液体。这 个特殊的現象可能与液晶态的結构有关。 M. G. Broadhurst, E. R. Fitzgelard and A. J. Bur, J. Appl. Phys., 32, 972 (1961)。 
体，然后再沿着其中的螺旋位錯中心作为发 展新层的晶核不断地向上盘旋生长变厚。

高聚物結晶过程最大不同于小分子物稹 的特征，是結晶轉变的不平衡性。由于高聚 物的許多特征，例如松弛时間很长，粘度很 大等动力学因素，往往使得它不能很好地結 晶而可以保持非晶态的結构。郎使完全长成 球晶，球晶中晶粒內部結构的完善程度，缺 陷的多少，也可以因結晶条件而有很大的差 别。晶粒間相互堆砌得不整齐，可以形成好 多微小的空隙、晶粒間界甚至相当大的裂 縫。这些因素都会影响高聚物产品的密度， 所以用膨胀計法測定結晶过程所得試样的最 終密度会有不同。过去有許多工作，籠統地 把这許多因素造成的密度变化都归因于高聚 物不能完全結晶，只能部分結唱，是不够要 当的。因此密度的差异和变化讲不能成为支 持高聚物具有两相結构的証据。

高聚物等温結晶时，在完成了符合 Avrami 方程的、密度迅速增加的快轉 变过 程以后，它的密度还会継續不断地随着結晶 时間而慢慢增加，与等温結 晶时間的对数 $\log \varepsilon$ 成值綫关系变化 ${ }^{[57]}$ 。有很多高聚物的等 温結晶曲綫則在符合 Avrami 方程式的 S 形 曲綫变化以后，又出現一个新的台阶（图 $26)^{[58]}$ 。这个䜌慢变化的过程叫做結晶的第 二阶段。覌察球晶的生长, 发現在球晶长大 到相互接触，完全变成球晶以后，球晶还会 継續变化，这些变化可能与球晶中晶粒的堆 砌更紧密, 晶粒內部缺陷的消除使晶体变得 更为完善有关。

高聚物有一个很大的特点，郎可以用各 种聚合方法制成分子量大小不同、分子量分 布不同的聚合物，用共聚、接枝、嵌段、交 联等方法来改变它的化学結构，这些結构特
点对高聚物結晶过程的影响是目前研究得不 多的重要力面。研究高聚物加工过程中，例 如拉伸过程中的結晶过程，也是一个重要的 和有很大实用意义的問題。

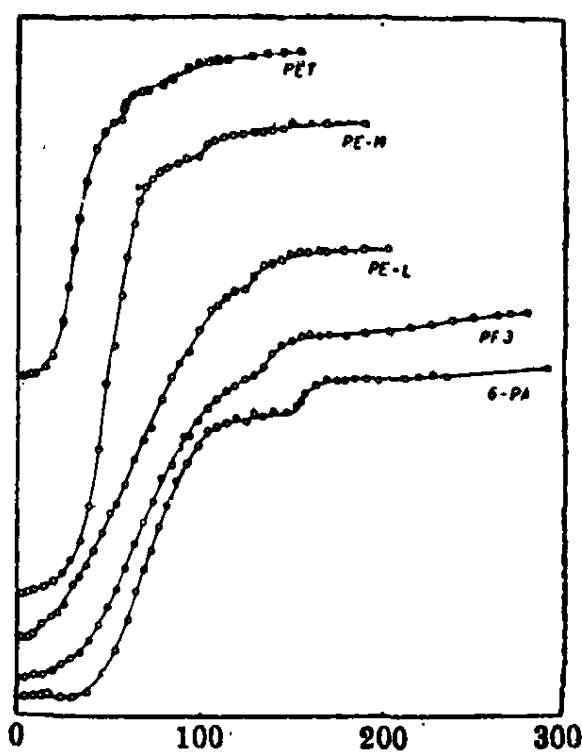

图 26 几种高聚物的等溫結晶曲䋐。都可 見显著的結晶第二阶段。（1）聚对苯二甲酸 乙二酯; (2)高密度聚乙烯; (3)低㖶度聚 乙烯;（4)聚三氟氮乙烯;（5)尼龙 6

\section{五 高聚物的聚集态結构問題}

（1）近年来，关于高聚物結晶形态、結 晶过程的大量研究表明，尽管高聚物有許多 不同于小分子物质的特点，但是两者依然邀 循着許多共同的基本規律。䦐明这些基本規 律的共同性是高聚物聚集态結构研究中一个 重大的进展。因为这些研究修正了我們以往 不正确的两相結构概念，闆明了高聚物結构 与性能之間的一些基本关系，为开展今后的 研究指明了一个正确的方向。人們对小分子 物稹結构、性能的大量政究，已經取得了巨 大的成就。最鮮明的例子是关于金属材料的 研究。可以利用金属材料聚集态結构的不 同，把組成相同(或者相差不多)的材料制成 具有各种不同工艺性能的产品。在研究工作 
方面，也已經建立和发展了一整套完善的研 究金属結构、性能的科学方法。可以設想， 用类似于金相学、金属物理学的方法来研究 高聚物的聚集态結构和聚集态結构对性能的 关系，对改进現有高聚物目前的各种使用性 能也将能够作出巨大的貢献。这种类似于研 究金属材料的研究方法, 近年来漸漸地受到 了大家的重視和注澺，在文献中已愈来愈多 地討論到球晶等聚集态結构对性能的关系， 利用类似的方法，如溶剂腐飿等方法，来研 究高聚物的聚集态結构。

（2）結晶度的問題。

既然高聚物在結晶时遵循着与小分子共 同的基本規律，則其所得的产物的聚集态結 构也应該和小分子的聚集态結构有許多类似 之点。設想一块金属或一块結晶石腊当然都 是完全結晶的, 其中没有什么不結晶的部 分，自然也就不存在結晶度大小的問題。应 該説，一块完全由单晶体或結晶聚集体（球 晶、多角晶等) 組成的高聚物也是完全結晶 的，其中没有不結晶的非晶相。高聚物的密 度往往低于由晶胞参数算得的理論密度, 很 可能是由于高聚物結晶較之小分子晶体有着 更多的結构缺陷、顆粒間界、晶粒堆砌得不 整齐和存在着微覌空隙的緣故，而不一定說 明高聚物中存在着非晶态部分。研究温度 对綫型聚乙烯 X-射綫衍射強度的变化（图

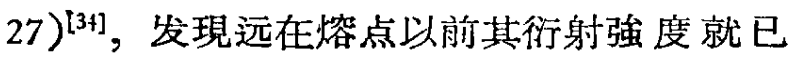
随着温度的上升而显著娍弱，扭在体积产生 突变、結晶熔化以前 $\left(130^{\circ} \mathrm{C}\right)$ ，結晶衍射崒 完全消失而代之以一个新的弥散峯。聚乙烯 試样 Marlex 50 的熔点为 $137.5 \pm 0.5{ }^{\circ} \mathrm{C}^{[52]}$ 。 这个实驗結果表明了,結晶性高聚物 $\mathrm{X}$-射綫 衍射图中的弥散峯，虽然表面上与非晶态結 构产生的弥散峯很相似，但是从高聚物的 X一
射綫衍射图有弥散峯这个实驗現象，升不能 得出弥散峯一定是由非晶态結构产生的，因 此結晶性高聚物中存在着非晶相的推埨。高 分子鏈結构的不規則性（支化、无規立构、

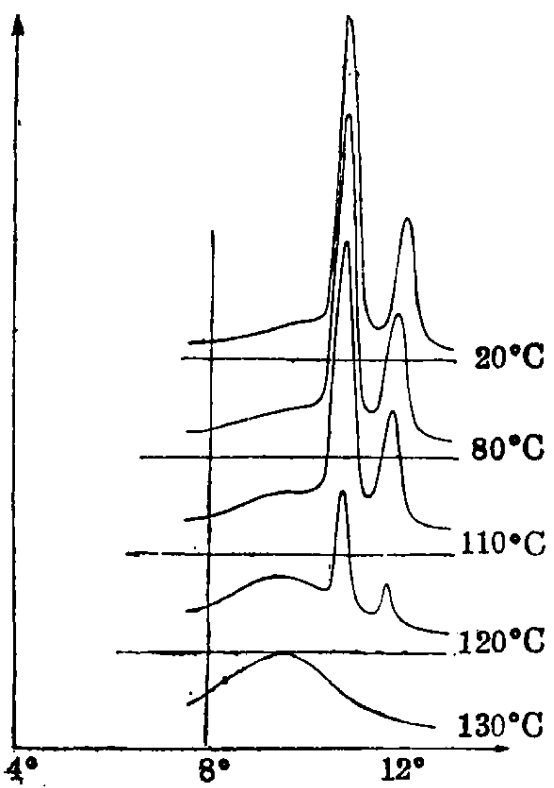

图 27 綫型聚乙烯 Marlex 50 X-射 綫衍射强度随溫度的变化关系图

分子鏈卷曲等）和昆体中的分子热运动，可 使得高聚物結晶点陣的缺陷不断增多、变大， 这些因素将使得結晶的衍射点強度逐漸減弱 拜湮沒在弥散的背景中。研究温度对綫型聚 乙烯紅外光謭強度变化的影响 ${ }^{[34]}$ (图 28)，

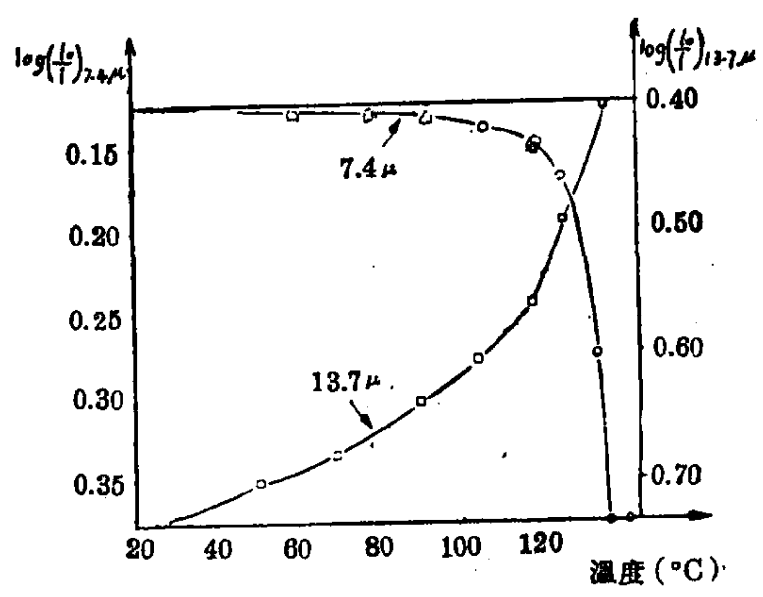

图 28 溫度对綫型聚乙烯 Marlcx 50 紅外光䜺强度变化的关系图 


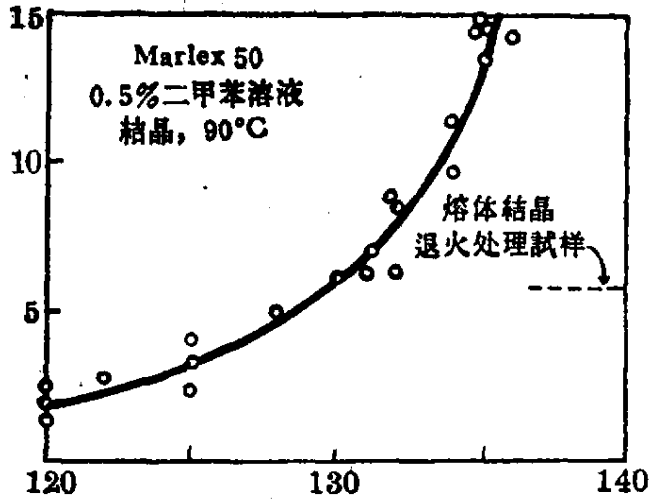

图 29 热处理溫度对䋐型聚乙烯 Marlex 50 单 晶体产生核磁共振譜践狄吸收带的变化关系图

发現用来作为測量結晶度的結晶带 $(13.7 \mu)$ 的强度随温度上升而逐漸減弱，而另一个吸 收譜带 (非晶带 $7.4 \mu$ ) 的強度則随温度的升高 而減弱得很少, 直到 $120^{\circ} \mathrm{C}$ 以后才有显著变 化。按照过去老的概念，这意味着闰一个高 聚物，据紅外光譜的測量，它的“結晶度” 随着温度的变化有着苪种截然不同的依賴关 系。这显然也很不合理，十分矛盾。

用核磁共振研究高聚物，常常把寬的吸 收带归因于晶态結构，而把狹的吸收峯归因 于非晶态結构, 銿用这两个吸收峯的面积比 例来估計高聚物的結晶度。最近，研究热处 理对綫型聚乙烯（Marlex 50）单晶体核磁共 振譜带的变化 ${ }^{[58]}$ ，发現从稀溶液中結晶所得 的单晶体只有寬的吸收峷而沒有狹的吸收 峯。但是，把这种单晶体在熔点以下的温度 热处理片刻后再冷却至室温，郎出現狹吸收 峷，吸吸收峷的強度随着热处理温度的提高 而境加(图 29)。这澺味着随着温度的增加, 单晶体中分子的热运动增加了，使得在单晶 体中产生了不少缺陷; 这些缺陷在試样冷却 后也不能全消除，因此晶体虽然沒有轉变 成非晶相物稹，“也会出現狹的吸收峯。总起 来㜔，各种用来測定“結晶度”的方法所測得 的結果，都讲不見得与高聚物非晶相結构部
分的百分比有什么精确的关系，而大多数只 是表示晶粒中缺陷的程度或分子热运动的程 度。而用各种方法測得的所請“結晶度”，我 不像它的定义所說的那样，表示高聚物中晶 相部分的百分比，而是沒有明确物理意义的。 它只是一个粗約表示高聚物聚集态結构状况 或加工过程中結构变化的工艺指标。高聚物 的結构是复杂的，高分子的种类很多，性稹 也各不相同，因此它們的聚集态結构也远較 金属、合金等无机体系的聚集态复杂得多。 由于长鏈分子結构的缺陷 (支化、交联、无規 立构等），晶相中的长鏈分子有褶迭的区域， 高聚物的結晶有着比小分子晶体更多的缺 陷。另一方面，由于长鏈分子中各个原子之 間有着固定不变的化学鍵的联系，长鏈分子 的巨大不对称性和分子鏈趋向于相互平行堆 砌，則使得高聚物非晶态的有序程度㜞小分 子的非晶态来得規則。又由于結晶动力学的 因素，高聚物結晶时往往不能生成結构完善 的大晶体，而停留在各种有序程度不同的中 間阶段。因此，类比高聚物和小分子多晶体 的聚集态結构，不宜机械地搬用小分子聚集 态結构的概念，生硬地把聚集态划分为晶 相、非晶相两部分。用各种力法研究聚集态 結构，更要小心注澺每个方法所測量的是什 么和它代表的真正物理意义。

(3) 拉伸的問題。

拉伸过程是高聚物加工工艺过程中很重 要的一个环节。拉伸能使高聚物产生取向, 获得許多优良的使用性能，可以成倍地提高 高聚物的強度，大大改进高聚物耐碎裂的性 稹。拉伸过程的本质是相当复杂的，不闹的 聚集态結构拉伸时表現出来的性稹，覌察到 的現象很不相同，其拉伸形变机制也各不相 问。就結晶性高聚物而言，对拉伸形变的解 
秚目前也还沒有取得一致，倫存在着孚論。 Müller 等訩为，拉伸过程是結晶熔化再結晶 的相轉变过程 ${ }^{[9,600]}$ 。但是在应力作用下，高 聚物的熔点是否真正能降低 $100 \sim 200^{\circ} \mathrm{C}$ 之 多，在拉伸过程中发生結晶熔化、再結晶的 相轉变过程，是頗令人怀疑的。

类比高聚物和小分子物盾（金属材料的） 形变过程，启示了我們: 这些由薄片状物、 針状物組成的聚集体在形变时的变化，可能 象金属的形变那样，主要是相互間結合力最 弱的晶面之間的滑移，較大較完整的晶粒被 撕裂成輘小的碎片。目前已有一些作者提出 这种說法 ${ }^{[61-64]}$ 。聚乙烯晶体的电子显微鏡观 察（图 30），更是值接地有力証明在应力作 用下高聚物結晶的形变，是片状結晶之間的 滑移，以及从片状体中拉出糿維状的束状体 的过程 ${ }^{34]}$ 。

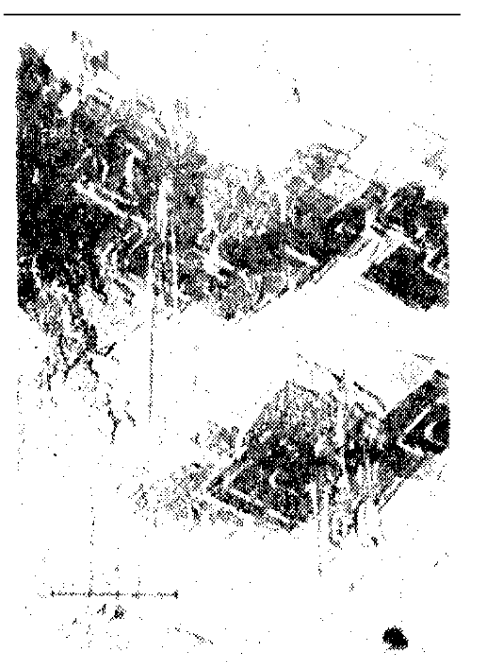

图 30 从聚乙稫单晶体中拉出䊹維状束状体 的电子显微照片

核磁共振的研究 ${ }^{[65]}$ 也証实，由于完整的大晶 粒被撕裂成碎片，拉伸取向后的綫型聚乙烯 栻样輘未經拉伸的試样有更多的缺陷。有一 些高聚物在拉伸过程中，的确同时发生从非 晶相变成晶相的相轉变，例如天然橡胶、聚 对苯二用酸乙二酯等等，这是因为在本常的
条件下它們的結晶速率很慢，长时期地保持 着非晶态的結构，在拉伸时应力的作用大大 加快了結晶的速率，使得在較短的实驗覌察 时間看到拉伸同时件随着相轉变过程。但 是，不能根据这个現象推想所有的高聚物在 拉伸时都有相轉变。如前所述，結晶高聚物 的形变过程主要是晶面滑移，使結晶聚集体 中取向机遇的微小晶粒，沿着某些一定的方 向有序排列起来成为各向异性体。而非晶态 高聚物郎使拉伸导致分子鏈取向，也沟有相 轉变发生。至于拉伸过程中有沒有細頸部的 生成, 有沒有光学性盾的改变, 我不能作为 判断有没有相轉变发生的可靠証据。典型的 非晶态高聚物，如聚甲基丙烯酸甲酯、聚苯

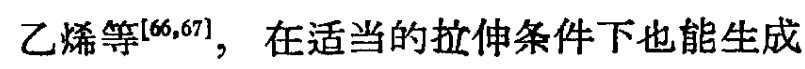
頸部，而結晶性的聚酰胺在适当的条件下拉 伸，也可以不产生頸部 ${ }^{[68]}$ 。

由于高聚物結构問題的复杂性和限于对 高聚物聚集态結构了解的水本，目前用正确 的結构覌点来深入研究高聚物形变过程的本 稹的工作，是做得很不够的。拉伸取向試样 的聚集态結构問題, 現在还很不清楚, 这是 一个今后需要仔細研究的重要問道。可以期 待, 在目前的基础上継續樑入研究下去，不 久即可統一分歧, 得到正确的訊識。

(4) 热处理的問題。

經常需要把高聚物加热到一定温度来进 行加工，高聚物产品在使用过程中也往往必 須承受各种不同温度的作用。不同的热处理 可以使得高聚物的結构发生变化，改变它的 性能。因此梁入了解热处理时高聚物的結构 变化的本盾和結构变化对性能的影响, 是一 个很重要和很有兴趣的問题。类比高聚物和 小分子物盾的聚集态結构，可以看到高聚物 結晶类似于小分子結晶，热处理可以使較不 
稳定的結构逐漸轉变成为較稳定的結构。非 晶态轉变成为結晶，或产生多晶轉变，使較 不稳定的結晶轉变成較为稳定的結晶, 例如 聚酰胺的 $\beta$-变体轉变成为 $\alpha$-变体 ${ }^{[69,70]}$ 。热 处理可以消除晶粒中部分缺陷, 使微小的、 . 結构缺陷較多的晶粒逐漸消失，而生成較大 的輘为完善的晶粒，郎有再結晶的过程。热 处理可以改善高聚物結晶的不本衡性，我使 球晶結构发生变化。适当的热处理可以改进 高聚物的性能，然而再結晶过程，晶粒虽然 趋于完普粗大, 却往往使得高聚物变脆, 性 能变坏。

結构的巨大改变，意味着高分子在晶体 中虽远在熔点以下已經有相当自由的分子运 动。用电子显微鏡覌察高聚物单晶体經热处 理后形态的改变, 可以看到片状結晶的厚度 随热处理温度的提高而变厚, 或隆起許多小 紴紋，随着結晶的变厚，在片状晶体中产生 了好些相当大的空洞和空隙 ${ }^{[71,72]}$ 。除了用电 子显微鏡直接覌察片状晶体变厚以外，測量 $\mathrm{X}$-射綫小角度散射的长周期, 可以更精确地 測量高聚物晶体厚度的变化。对各种高聚物 (聚乙烯、聚酰胺、聚酯等等)长周期湘量的 結果, 也都表明随着热处理温度的提高, 結

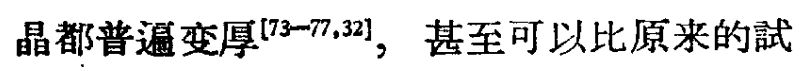
样厚三四倍之多。这是十分有趣的現象, 如 前所述，我們知道在高聚物晶体中，长鏈分 子是規則地反复槢迭起来的, 那末結晶的变 厚意味着远在熔点以下分子鏈就早已能够在 晶体中十分自由地移动、褶迭，并随着温度 的提高再槢迭成为更厚的薄片。电子显微鏡 覌察到片装晶体中的空洞就是由于热处理

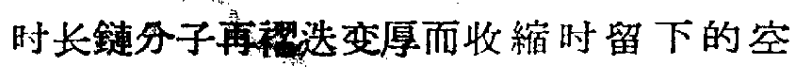
㿟。图 31 是聚乙情单晶体热处理后的电子 显微照片, 可以很清楂地看到晶体形状的变
化和空洞的产生。图 32 是聚乙烧单晶体聚 集体长周期随热处理温度的变化关系，可以 看到热处理时长周期的改变是相当巨大的。 干燥的单晶体在热处理时，长周期噵着热处 理的温度不可逆的䝬大, 試样冷却至室温后 測定也不再变短。如果把单晶体分散在液体 介盾中热处理，則随荍温度的高低会发生可 逆的变化，长周期能变大，也能够变小 ${ }^{[29]}$ 。

\section{图 31 聚乙烯单晶体的电子显微肧片。桱 $120^{\circ} \mathrm{C}$ 热处理后晶体变厚，隆起䊺故，边緗 残缺不齐讲产生空洞}

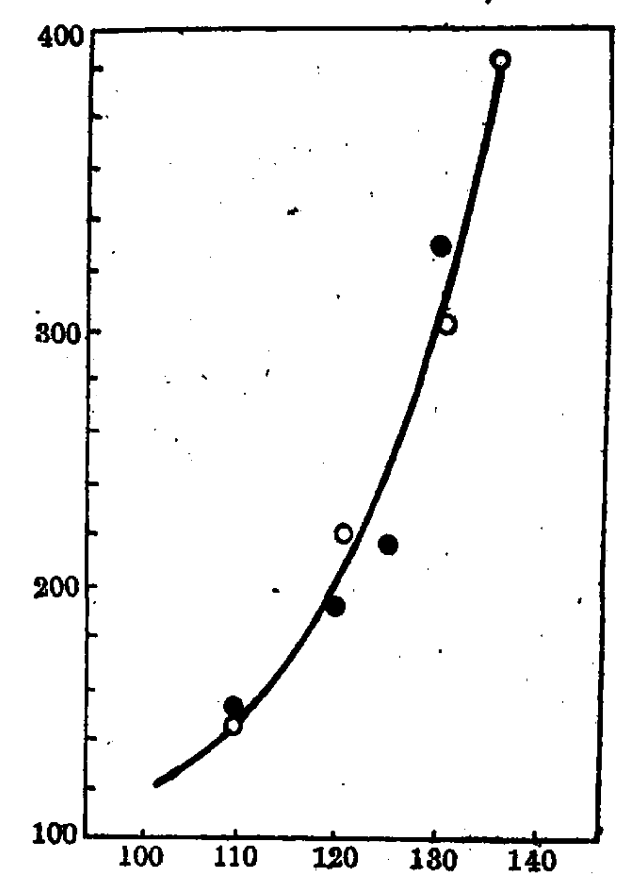

图 32 聚乙烯单晶体压块 X一射践小角度散射 长周期随热处理温度的变化关䒺图 在文献中，用电子显微鏡覌察单晶体形状变 化科配合以 $\mathrm{X}$-射綫小角度散射測量长周期 
变化的，几乎只限于結构最簡单的、分子鏈 没有极性的聚乙烯一种。扩大研究的对象， 㨁接覌察分子鏈之間有較強相互作用的高分 子单晶体在热处理时結构如何变化，分子鏈 怎样进行再褶迭, 是很有意思的, 这些研究 将有助于丁解晶态中分子鏈的运动和再褶迭 、的机制，以及小角度散射长周期的本稹。例 如, 已知聚酰胺䊹維的长周期随热处理的温 度而逐漸增加 ${ }^{[73,74]}$ (图 33)，但是为了满足分 子鏈之間氫鍵的相互作用，最好应該以結构 重复单元为再䂏迭的最小单位进行跳跃式的 再褟迭。究竟在热处理时这类高聚物单晶体 的結构如何变化，有待于今后更多的实驗工 作来丰富我們的知識。由于高分子在晶体中 槢迭的方式不同，可以使得所生成的晶体熔 点不同，研究聚乙烯六边形空心稜錐晶体經 热处理后的变化，发現經 $128-130^{\circ} \mathrm{C}$ 处理 后，空心稜錐状晶体沿 (100) 面生长的部分 熔化不見，而只剩下沿（110）面生长的部 分 ${ }^{[78]}$ 。

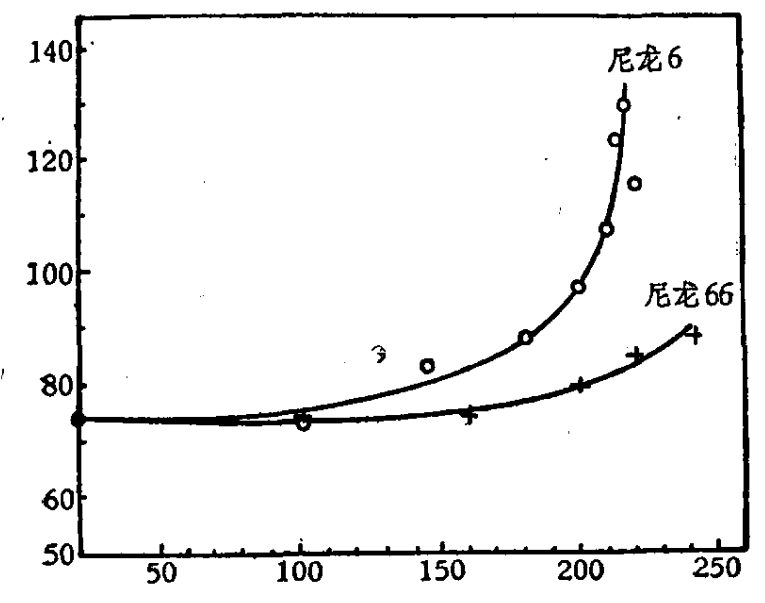

图 33 热处理溫度对聚酰胺糿維长周期 变化的影响

（5）. 高聚物的非晶态結构問題。

結晶形态和結晶过程的研究, 使我們对 高聚物的晶态結构有了一个正确的了解。然
而直到最近, 对于高聚物的非晶态結构还是 很不清楚的。以往大家都普遍訩为，柔性鏈 的綫型高聚物在非晶态傾向于緾結起来，卷 曲成为无規綫团。高聚物的非晶态結构是不 是真的繶結得很厉害, 杂乱无序得很呢? 从 晶态結构的研究，我們知道在結晶中长鏈分 子区复褶迭得十分整齐，具有三維长程有序 的点陣結构。从結晶速率的研究, 我們知道 有許多高聚物从非晶态到晶态的轉变过程进 行得十分迅速。从分子运动的㸴究，我們則 知道大分子的松驰是一个相当慢的过程, 需 要相当长的松弛时間。怎样来設想一堆縓結 卷曲起来、松扡时間很长的无規綫团能在短 的时間內相互解开，然后迅速地褶迭起来， 堆砌排列成为規則的晶态呢? 为了統一这些 实驗事实和旧有的非晶态結构概念之間的矛 盾, $\mathrm{Kаргин}^{[7]}$ 訩为必須要修改非晶态是總 結的无規綫团的模型，訩为高聚物的非晶态 結构利不象以往想象那样的縓結、混杂，而 是相当有序的。有些非晶态高聚物的长鏈分 子也能相互本行地取向排列，聚集成为有规 則几何外形的鏈束 ${ }^{[80]}$, 規則的几何外形郎为 长鋉分子有序排列的宏覌反映; 他們更用小 区域电子衍射的方法，直接証明鏈束中的分 子排列是有取向的。非晶态的高聚物有时能 够成为球状結构单元(鏈球)的聚集体，测量 每个鏈球的大小和測定高聚物的分子量，估 計鏈球是由一个分子参曲而成的，而整块非 晶态高聚物則由許多个鏈球聚集而成。

不同于一般小分子固体，非晶态是高聚 物特別重要的聚集态。一般小分子固体几乎 絕大多数都是結品物稹。因此, 高聚物的非 晶态結构是䂰究高聚物的結构、性能不可忽 視的重要环节。可是，目前对于高聚物非晶 态結构的了解远远比高聚物的晶态不清楚得 
多，有待合后的研究。

\section{六 結 語}

回頋近年来高聚物結晶研究的进展，可 以看到許多传統的概念、想法、模型都与实 驗事实有很大的矛盾，必須进行修改或者甚 至完全推翻。可以說，高聚物結构的研究目 前正处于一个革命变革的时期。可以看到， 尽管高分子有很多不同于小分子的特点，但 是两者仍然有很多共同之点，从非晶态到唱 态的轉变过程，結晶生长的形态等都遵循着 共同的基本規律。为了扯轉以往不正确的覌 念，本交特別強調地类比了高聚物和小分子 物盾的共同性。应該指出，高聚物既然具有 一系列不同于小分子物稹的結构特点，那末 在共性之外，它必然还会有許多有別于小分 子物质的特殊性质。研究高聚物的結构、性 能时，必須要考虑到这些特殊性的問題。应 該說，高聚物聚集态結构的正确研究还只是 刚刚开始，目前的研究大多数还只局限于少 数几种結构規則的綫型高聚物。这些研究的 結果，固然能够代表高聚物結构的基本規 律，但是毕䙾还只是一些概括性的基本規 律，还无法完满地解释清楚許多高聚物特有 的性盾。好些实驗現象之間，理論和实驗之 間；都还存在着不少无法解释的矛盾。結合 高聚物結构的特点，扩大研究的領域，䂰究 各种类型化学結构不同的高聚物，各种支化 程度、交联程度不同的高聚物、共聚物、接 枝共聚物、嵌段共聚物的結晶問題，研究分 子最、分子量分布对結晶速率的影响，揭露 高聚物特有的規律，是今后研究的重要方 向。这些碎将更进一步闈明高聚物的本 稹，为結构变化和性能之間关系的深入了解 提供稳固的科学基础。
致謝：承蒙錢人元敉授指导写作，特此致以深 切謝意。

[1] S. Nishikawa \& S. Ono, Proc. Phys. Math. Soc. Japan, .Sept. 20 (1913).

[2] O. Gerngross, K. Herrmann \& W. Abitz, Z. Physik Chem., B10, 371 (1930).

[3] В. А. Каргин, Г. Л. Слонимский, 高分于通訊， 4, № 3, (1960).

[4] A. Keller, R. H. Doremus, B. W. Roberts, D. Turnbull 編的 "Growth \& Perfection of Crystals". John Wiley \& Son, New York (1958), 第 499 面; A. Keller, Makromol. Chem., 34, 1' (1959).

[5] W. Schlesinger \& H. M. Lecper, J. Polymer Sci., 11, 203 (1953).

[6] R. Jaccodine, Nature (London), 176, 305 (1955).

[7] A. Keller, Phil. Mag., 2, 117' ' (1957).

[8] P. H. Till, J. Polymer Sci., 24, 301 (1957).

[9] E. W. Fischer, Z. Naturforsch., 12a, 753: (1957).

[10] P. H. Geil, N. K. J. Symons \& R. G. Scott, J. Appl. Phys., 30, 1516 (1959).

[11] D. H. Reneker, P. H. Geil, J. Appl. Phys., 31, 1916 (19601).

[12] A. Keller, J. Polymer Sci., 36, 361 (1959).

[13] P. H. Geil, J. Polymer Sci., 44, 449 (1960).

[14] В. А. Қаргин, Вестник АН СССР, 31, № 4, 19 (1961).

[15] B. G. Rảnby, F. F. Marehead \& N. M. Walter, J. Polymer Sci., 44, 349 (1960).

[16] В. А. Каргин, Н. Ф. Вакеев, 李历生, Т. С. Очановская, Высокомол. соединеияя, 2 2, 1280 (1960).

[17] F. C. Frank, A. Keller \& A. O'Connor, Phil. Mag., 4, 200. (1959).

[18] M. L. Miller, M. C. Botty \& C. E. Rauhut, J. Colloid Sc̈i., 15, 83 (1960).

[19] B. G. Rånby, C. \& E News (1960) No. 7. 53; B. G. Rånby, J. Polymer Sci., 51, 337 (1961).

[20] F. Khoury \& F. J. Padden Jr., J. Polymer Sci., 47, 455 (1960).

[21] A. Keller, Discussion Faraday Soc., 25, 114 (1958).

[22] A. Keller, A. O'Connor, Polymer, 1, 163 (1960).

[23] F. C. Frank, Discussion Faraday Soc., 25, 208 (1958).

[24] R. Eppe, E. W. Fischer \& H. A. Stuart, J. Polymer Sci., 34, 721' (1959).

[25] J. I. Lauritzen \& J. D. Hoffman, J. Research Natl. Bur. Standards, 64a, 73 (1960).

[26] J. I. Lauritzen \& J. D. Hoffman, J. Chem. Phys., 31, 1680 (1959).

[27] F. P. Price, J. Chem. Phys., 31, 1679 (1959).

[28i] A. Peterlin, J. Appl. Phys., 31, 1934 (1960).

[29] B. G. Rånby \& H. Brumberger, Polymer, 1, 399 
(1960).

[30] W. D. Neigisch \& P. R. Swan, J. Appl. Phys., 31, 1906 (1960).

[31] D. C. Bassett, A. Keller, Phil. Mag., 6, 345 (1961).

[32] E. P. H. Meibohm, A. F. Smith, J. Polymer Sci., 7, 449 (1951).

[33] R. Helmut, Faserforsch und Textiltechn., 8, 224 (1957).

[34] H. A. Stuart, Annals of New York Academy of Sciences, 83, 3 (1959).

[35] F. C. Frank, Discussion Faraday Soc., 5, 48 - (1949).

[36] A. M. Verma, "Crystal Growth \& Dislocations", London, Butterworths (195.3).

[37] A. Keller, Makromol. Chem., 34, 17 (1959)

[38] P. H. Geil, J. Polymer Sci., 47, 64 (1960).

[39] C. W. Bunn, A. J. Cobbold \& R. P. Palmer, J. Polymer Sci., 28, 365 (1958).

[40] G. Schuur, "Some Aspects of Crystallization of High Polymers", Rubber Stichting Delft Commu. Nr. 276 (1955).

[41] F. J. Padden, Jr. \& H. D. Keith, J. Appl. Phys., 30, 1479 (1959).

[42] H. D. Keith, F. J. Padden, Jr., N. M. Walter \& H. W. Wyckoff, J. Appl. Phys., 30, 1485 (1959).

[43] C. R. Lindegren, J. Polymer Sci., 50, 181 (1961).

[44] F. Khoury, J. Polymer Sci., 33, 389 (1958).

[45] E. P. Price, Annals of New York Academy of Sciences, 83, 20 (1959).

[46] P. H. Geil, "Growth \& Perfection of Crystals" (1958), 第 579 面. R. H. Doremus 等編.

[47] 徐端夫、錢人元，中国科学院第三次高分子会議会 刊 (1961).

[48] A. Keller, J. R. S. Waring, J. Polymer Sci., 17, 447 (1955).

[49] F. Danusso, Makromol. Chem., 35A, 80 (1960).

[50] R. St. J. Manley, J. Polymer Sci., 47, 509 (1960).

[51] 植公市. 毁, 高分子, 9, No. 100, 485 (1960).

[52] L. Mandelkern, "Growth \& Perfection of Crystals" (1958), 第 467 頁. R. H. Doremus 等編.

[53] I. Mandelkern, Chem. Rev., 56, 903 (1956).

[54] A. S. Kenyon, R. C. Gross \& A. L. Wurstner, I. Polymer Sci., 40, 159 (1959).

[55] P. J. Flory \& A. D. Mclntyre, J. Polymer Sci., 18, 592 (1955).

[56] A. Kovacs, Recerca Sci., 25A, 668 (1955).
[57] F. Rybnikar, J. Polymer Sci., 44, 517 (1960).

[58] W. P. Slichter, J. Appl. Phys., 31, 1865 (1960).

[59] F. H. Müller, Kolloid Z., 115, 118 (1949).

[60] Г. Л. Слонимский, 高分子通訊, 4, 150 (1960).

[61] R. Westrk, Discussion Faraday Soc., 25, 206 (1958).

[62] F. C. Frank, A. Keller, A. O'connor, Phil. Mag., 3, 64 (1958).

[63] I. L. Hopkins \& W. O. Baker, 䄇看 F. R. Eirich 䋧的 Reology Vol. III，第十章 365 面 (1960), Academic Press, New York \& London, 及其所引 之交献.

[64] C. Sella \& J. J. Trillat, Compt. rend., 248, 410 (1959').

[65] W. P. Slichter, "Growth \& Perfection of Crystals" (1958), Doremus 等編, 第 558 頁.

[66] E. A. W. Hoff, J. Appl. Chem., 2, 441 (1952).

[67] K. Jackel, Kolloid Z., 137, 130. (1954).

[68] H. Yumoto, Bull. Chem. Soc. Japan, 29, 141 (1956).

[69] C. W. Bunn, E. V. Garnet, Proc. Roy. Soc., 189, 39 (1947).

[70] D. R. Holmes, C. W. Bunn, D. J. Smith, I. Polymer Sci., 17, 159 (1955).

[71] W. O. Statton, P. H. Geil, J. Appl. Polymer Sci., 3, 357 (1960).

[72] 4井西夫、光畑照久、山下祐崖，高分子化学，18， No. 189,33 (1961).

[73] E. W. Fischer, Annals of New York Academy of: Sciences, 89, 620 (1961).

[74] K. Hess, Recerca Sci,, 25A, 594 (1955).

[75] H. Zahn, Melliand Textilbor, 32, 53:4 (1951).

[76] L. M. Arnett, E. P. H. Meibohm, A. F. Smith, J. Polymer Sci., 5, 737 (1950).

[77] K. Hess, H. Kiessig, Z. Phys. Chem., 193, 196. (1944).

[78] D. C. Bassett, F. C. Frank, A. Keller, Nature, 184, $810(1959)$.

[79] В. А. Каргин, J. Polymer Sci., 48, 1 (1960).

[80] В. А. Каргин, Н. В. Бакеев, Х. Вергин. ДАН CCCP, 122, № 1, 97 (1958).

附陆: 最近, Marchessault 等报导的聚 $d$-木糖酕单.晶体 的电子显微照片，再一次証明了这个碳水化合物 六角形片状的唱体中，分子鏈也是規則福迭的 [R. H. Marchessault, F. I. : Moreheacl, N. M. Walter, C. P. J. Glaudemans, \& T. E. Timell, J. Polymer, Sci., 51, No. 156, 566, (1961)]. 